\title{
Cord Lipoma - An Analogue of Preperitoneal Fat: A Laparoscopic Study
}

\author{
Running Title: Lipoma of Spermatic Cord \\ Maulana M. Ansari, MS (Surgery)
}

Professor of General Surgery, Department of Surgery, J. N. Medical College, Aligarh Muslim University, Aligarh, UP, India

\begin{abstract}
Sizable lipomas of spermatic cord were observed in the inguinal canals of 20 percent of adult male patients ( $N=25)$ who underwent laparoscopic total extra-peritoneal (TEPP) hernioplasty $(N=30)$ for inguinal hernia. All cord lipomas were associated with a hernial sac - indirect $83 \%$ and direct $17 \%$. Two-third of cord lipomas were small $(1-2 \mathrm{~cm})$ while one-third were moderate $(2-4 \mathrm{~cm})$ in size. All consisted of unencapsulated localized condensation of large easily separable fat globules composed of mature adipose tissues which was in direct continuity with preperitoneal fat of inguino-pelvic region along with vascular connections. Lipomas along with cord structures were enclosed within the internal spermatic fascia which was continuous with preperitoneal fascia covering the preperitoneal fat. Present study confirms that the so-called cord lipoma is really an analogue of preperitoneal fat and that dedicated laparoscopic work is required to realize their actual significance especially with respect to the cause-and-effect relationship with herniation.
\end{abstract}

Keywords: Cord lipoma, lipoma of spermatic cord, preperitoneal fat, TEP, total extra-peritoneal hernioplasty

\section{Introduction}

A lipoma of the spermatic cord (or round ligament) is defined as an isolated discrete collection of fatty tissue in and around the cord structures within the inguinal canal. The cord lipomas are often encountered during inguinal hernioplasty but receive little attention of the operator other than an incidental finding in association with hernia $[1,2]$. They are excised without bothering much about its anatomy, pathology, its relationship with adjacent structure/organ and its relationship/role with respect to herniation. Laparoscopic hernioplasty has thrown new light on them. Herein, we describe our findings about the so-called cord lipomas and its relationship with the preperitoneal fat observed during the laparoscopic total extra-peritoneal (TEPP) inguinal hernioplasty.

\section{Material and Methods}

A prospective study was designed and conducted w.e.f. April, 2010 at Jawaharlal Nehru Medical College \& Hospital, A.M. University, Aligarh in adult patients with uncomplicated primary inguinal hernia undergoing total extra-peritoneal (TEPP) mesh repair. Institutional Ethics Committee approval was obtained, and patients (ASA grade I-II) above 18 years of age were operated under the informed consent. The same TEP technique as reported earlier by the author was followed [3]. Patients with femoral hernia and recurrent/complicated inguinal hernia were excluded from the study. Actual study started from $28^{\text {th }}$ February, 2011 when the $1^{\text {st }}$ TEPP hernioplasty was performed and the interim results upto March, 2013 were analysed and are presented herein.

\section{Results}

Thirty TEPP procedures were done in 2 years in 25 male patients with a mean age of $49.7 \pm 17.6$ years. Inguinal hernia was unilateral 20 , bilateral 5 , indirect 27 , and direct 3 .
In 6 of these cases, there was a significant cord lipoma from small size of $1-2 \mathrm{~cm}(\mathrm{~N}=4)$ to moderate size of $2-4 \mathrm{~cm}$ $(\mathrm{N}=2)$. Five lipomas were associated with indirect inguinal hernia (Figure 1-3) while one lipoma was seen along the direct inguinal hernia (Figure 4). In each case, it consisted of a localized condensation of fibro-fatty tissues with large fat globules and there was no encapsulation but it was enclosed along with the cord structures within the internal spermatic fascia which was continuous with the preperitoneal fascia covering the preperitoneal fat of the inguino-pelvic region as seen clearly in the Figures 1 and 3. The fat globules of the cord lipomas were easily separable from each other as well as from the cord structures during dissection (Figure 3). In all patients, the cord lipoma was found tapering distally and continuous with the fibrofatty tissues of cord structures in the inguinal canal, giving it an elongated shape rather than a rounded shape as seen in other parts of the body (Figure 13 ); moreover, the lipomas were also in continuity with the preperitoneal fat of both the inguinal region ventrally and the pelvic region dorsally. The cord lipoma had much more vascular connections with that of the preperitoneal fat as compared to the cord structures, i.e., the lipoma was easily detachable from the cord structures without any significant bleeding but the operating site used to become rather bloody on its detachment from the preperitoneal fat. The preperitoneal fat layer was moderately fatty in 5 patients and excessively fatty in 1 patient with a moderate-sized lipoma. Lipomas were easily excised and removed piecemeal through the $10-\mathrm{mm}$ port using a 5-mm laparoscope through the middle working port, and histopathology did not reveal a ,true ${ }^{\text {ee }}$ lipoma in terms of benign neoplasia in any of the six cases.

\section{Discussion}

Presence of cord lipoma is usually considered as an incidental finding during hernia surgery [1]. Incidence of $20 \%$ in the present laparoscopic study is agreement with that of $19.6 \%$ recently reported in 2002 by Lilly and Arregui [1]. Way back in 1946, Tobin and associates documented that 


\section{International Journal of Science and Research (IJSR) \\ ISSN (Online): 2319-7064 \\ Index Copernicus Value (2013): 6.14 | Impact Factor (2014): 5.611}

lipomas of the spermatic cord are fatty protrusions of the preperitoneal fat into the inguinal canal [4], and this has been, in recent years, supported by Nyhus et al (1991), Read and Scaefer (2000), Heller et al (2002) and Carilli et al (2004) [5-8]. Present study also confirms that the cord lipoma is a continuation and condensed analogue of the preperitoneal fat in a way similar to the well-known analogues of the Transversalis fascia. However, Fawcett and Rooney (1997) mentioned that a cord lipoma present within the inguinal canal may not have connection with the preperitoneal fat, and termed it a ,true ${ }^{\text {ee }}$ lipoma even in absence of any feature of benign neoplasia; these authors reported such a ,true ${ }^{\text {ec }}$ lipoma in a very small percentage of $0.7 \%$ while the (pseudo) lipomas were seen in a much higher percentage of $32.8 \%$ in a series of 140 patients [9]. Vashu and Subramaniam (2009) reported a truly Neoplastic ,lipoma ${ }^{\text {ee }}$ of cord distal to the superficial inguinal ring, for the first time to the best of the authores knowledge although these workers did not claim so [10]. A few other reports of true lipoma of cord appeared further in the literature $[11,12]$ but all were distal to the superficial inguinal ring in a rather paratesticular location, the origin of which has been suggested from the development of local pluripotent cells into adipocyte lines [11]. Lilly and Arregui (2002) reported that the cord lipoma is, by definition, ,indirect ${ }^{\text {ee }}$ in nature and observed in $74.4 \%$ of the 43 lipomas associated with inguinal hernia but also detected in association with direct hernias albeit in a much smaller percentage of $25.6 \%$ [1]. Present study also recorded one out of six lipoma in relation to the direct hernia in $16.7 \%$ as opposed to $83.3 \%$ of cord lipoma associated with indirect hernia, although the incidence of the cord lipoma in patients with indirect and direct hernia was $18.6 \%$ and $33.3 \%$ respectively, that may be reflective of small sample size of the present study.

Heller et al (2002) suggested a developmental etiology of the cord lipoma [7]. Moreover, Lilly and Arregui (2002) suggested a possible cause-and- effect relationship that the lipomatous lobular preperitoneal fat in the inguinal region may insinuate through the deep inguinal ring and may dilate it over the time as a predisposition to indirect hernia formation [1], i.e., cord lipoma may act as a pile driver operator that drags out a part of the peritoneum into the inguinal canal. Cord lipoma, if not excised during hernia surgery, may be a cause of persistent symptoms or even a pseudo-recurrence of hernia as reported by a number of clinical investigators [1,2,13-15], and therefore excision of the cord lipomas are always recommended.

Despite being always continuous with the preperitoneal fat, no significant correlation was detected by Heller et al (2002) between the cord lipoma mass and age or BMI (body mass index) of the person [7]. We also did not find any correlation between the size of the cord lipoma and the thickness of the preperitoneal fat layer with which it was found consistently continuous with.

Tobin et al (1946) hinted that these lipomas may originate from the intermediate stratum of three embryological strata, from which the extraperitoneal connective tissues develop during the abdominal wall development [4]. Heller et al (2002) also suggested a developmental origin of the cord lipomas based on their high prevalence, characteristic location and appearance of the ,lipoma ${ }^{\text {ee }}[7]$.

\section{Conclusions}

Present study confirms that the so-called cord lipoma is really an analogue of the preperitoneal fat, and the author strongly recommends for dedicated work by laparoscopic hernia surgeons to realize their actual significance especially with respect to the cause-and-effect relationship with herniation.

\section{Conflict of Interest}

None

\section{Funding}

Nil

\section{References}

[1] Lilly MC, Arregui ME. Lipomas of the Cord and Round Ligament. Ann Surg 2002; 235(4): 586-590.

[2] Nasr AO, Tormey S, Walsh TN. Lipoma of the cord and round ligament: an overlooked diagnosis? Hernia 2005; 9: 245-247.

[3] Ansari MM. Effective Rectus sheath canal: Does it affect total extraperitoneal approach for inguinal mesh hernioplasty. J Exp Integr Med 2013; 3(1): 73-76.

[4] Tobin CE, Benjamin JA, Wells JC. Continuity of the fasciae lining the abdomen, pelvis, and spermatic cord. Surg Gynecol Obstet 1946; 83(5):575-96.

[5] Nyhus LM, Bombeck CT, Klein MS. Hernias. In Sabiston DC, ed. Textbook of Surgery: The Biological Basis of Modern Surgical Practice, 14th ed. Philadelphia: WB Saunders; 1991: 1134-1148.

[6] Read RC, Scaefer RF. Lipoma of the spermatic cord, fatty herniation, liposarcoma. Hernia 2000; 4(3): 149154.

[7] Heller CA, Marucci DD, Dunn T, Barr EM, Houang M, Remedios C. Inguinal canal "lipoma". Clin Anat 2002; 15(4): 280-284.

[8] Carilli S, Alper A, Emre A. inguinal cord lipomas. Hernia 2004; 8(3): 252-254.

[9] Fawcett AN, Rooney PS. Inguinal cord lipoma. Br J Surg 1997; 84(8):1169.

[10] Vashu R, Subramaniam M. Large lipoma of the spermatic cord presenting as post-operative recurrent hernia in a middle aged gentleman: a case report. Cases Journal 2009; 2: 8500.

[11]Edelstein RA. Giant spermatic cord lipoma. The Scientific World Journal 2009; 9: 1194-1196.

[12] Wronski K. Surgical treatment of giant spermatic cord lipoma - case report. Strona internetowa czasopisma New Medicine 2013; 2: s. 44-46.

[13]Felix E, Scott S, Crafton B, et al. Causes of recurrence after laparoscopic hernioplasty. Surg Endosc 1998; 12: 226-231.

[14] Gersin KS, Heniford BT, Garcia-Ruiz A, Ponsky JL. Missed lipoma of the spermatic cord: A pitfall of 


\section{International Journal of Science and Research (IJSR) \\ ISSN (Online): 2319-7064 \\ Index Copernicus Value (2013): 6.14 | Impact Factor (2014): 5.611}

transabdominal preperitoneal laparoscopic hernia repair. Surg Endosc 1999; 13: 585-587.

[15] Lan H, Loong F, Yuen WK, Patil NG: Management of herniated retroperitoneal adipose tissue during endoscopic extraperitoneal inguinal hernioplasty. Surg Endosc 2007;21(9): 1612-1616.
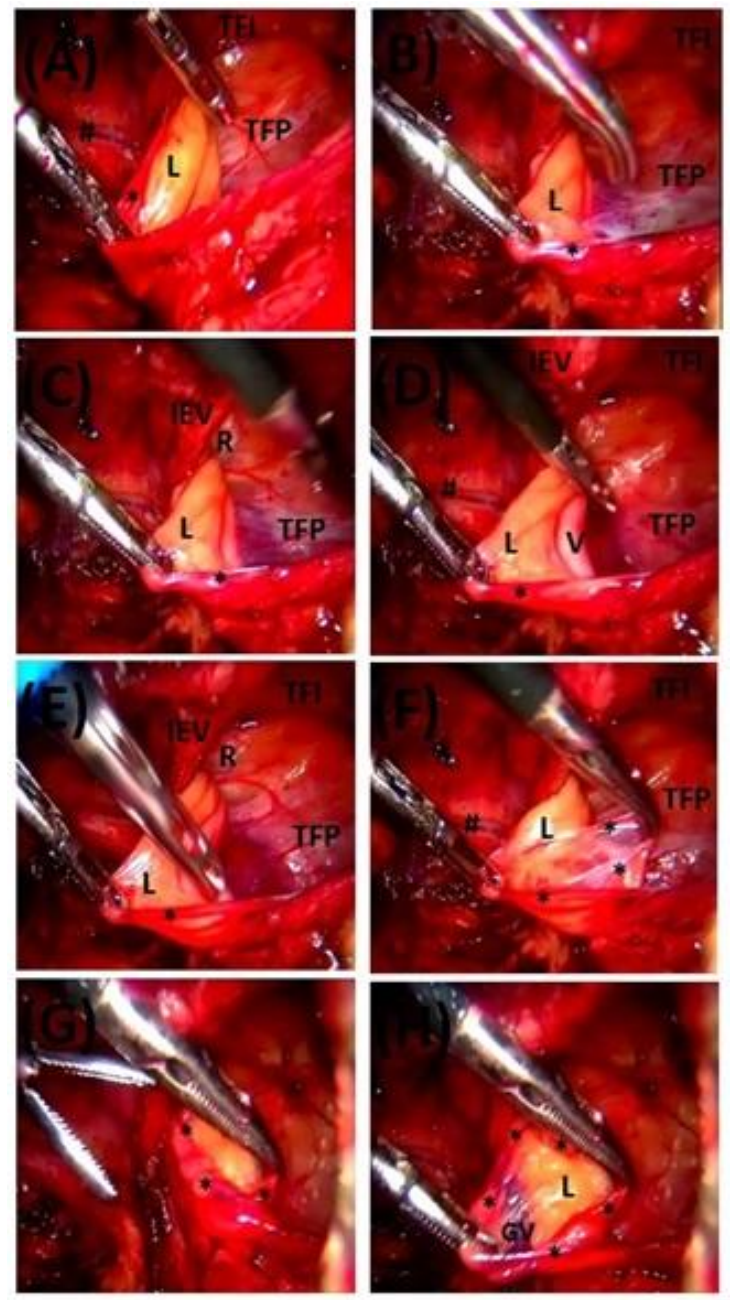

Figure 1: Total extra-peritoneal (TEP) hernioplasty dissection in one patient with right indirect inguinal hernia with cord lipoma: A, Dissection lateral to the indirect hernia;

B-H, Dissection medial to the indirect hernia; A-D, Cord lipoma (L) \& cord structures enclosed in the preperitoneal fascia (Marked by asterisk *), already dissected off the inguinal Transversalis fascia (TFI) and being dissected off the pelvic Transversalis fascia (TFP); E-H, Preperitoneal fascia (*) being teased off to expose the cord lipoma (L); IEV, deep inferior epigastric vessels covered by TFI; \#, corona mortis covered by Transversalis fascia; $\mathrm{GV}$, gonadal vessels (cord structures are rotated medially for dissection from lateral aspect).

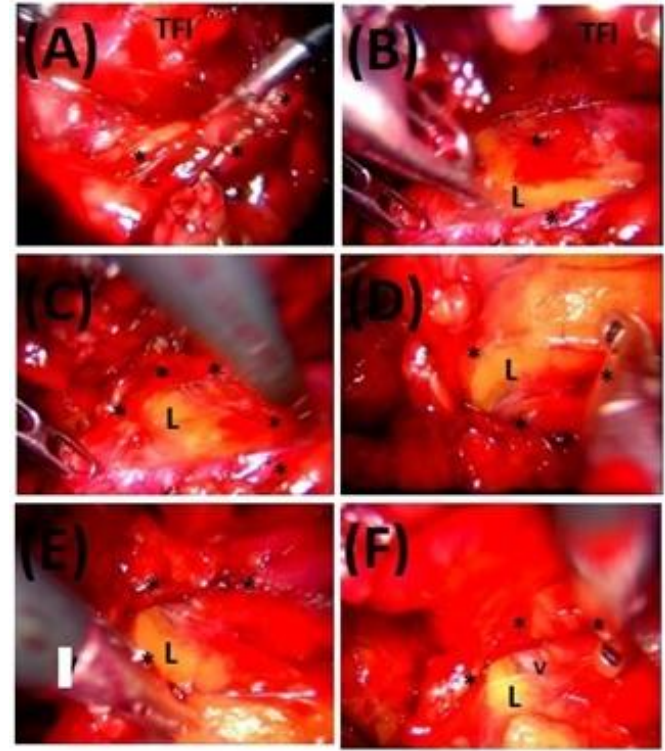

Figure 2: Total extra-peritoneal (TEP) hernioplasty dissection in another patient with right indirect inguinal hernia with cord lipoma: A, Cord lipoma (L) \& cord structures enclosed in the preperitoneal fascia (Marked by asterisk *), being dissected off the inguinal Transversalis fascia (TFI); B-F, Preperitoneal fascia (*) being teased off to expose indirect hernial sac (not yet seen due to presence of sizable cord lipoma (L), vas deferens (V) and other cord structures.
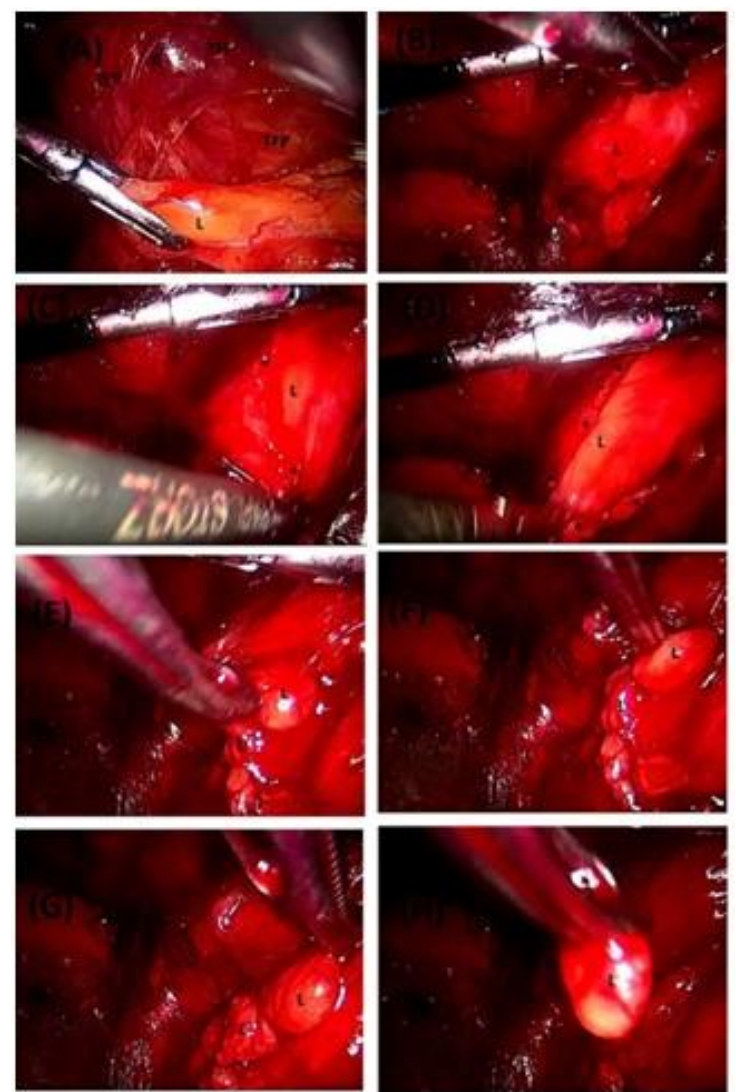

Figure 3: Total extra-peritoneal (TEP) hernioplasty dissection in a third patient with right indirect inguinal hernia with cord lipoma: A-D, Cord lipoma (L) \& cord structures enclosed in the preperitoneal fascia (Marked by asterisk *) which is being teased off to expose the sizable cord lipoma (L); E-F, cord lipoma having multiple large globules is being removed piecemeal.

\section{Volume 4 Issue 12, December 2015}




\section{International Journal of Science and Research (IJSR) \\ ISSN (Online): 2319-7064}

Index Copernicus Value (2013): 6.14 | Impact Factor (2014): 5.611

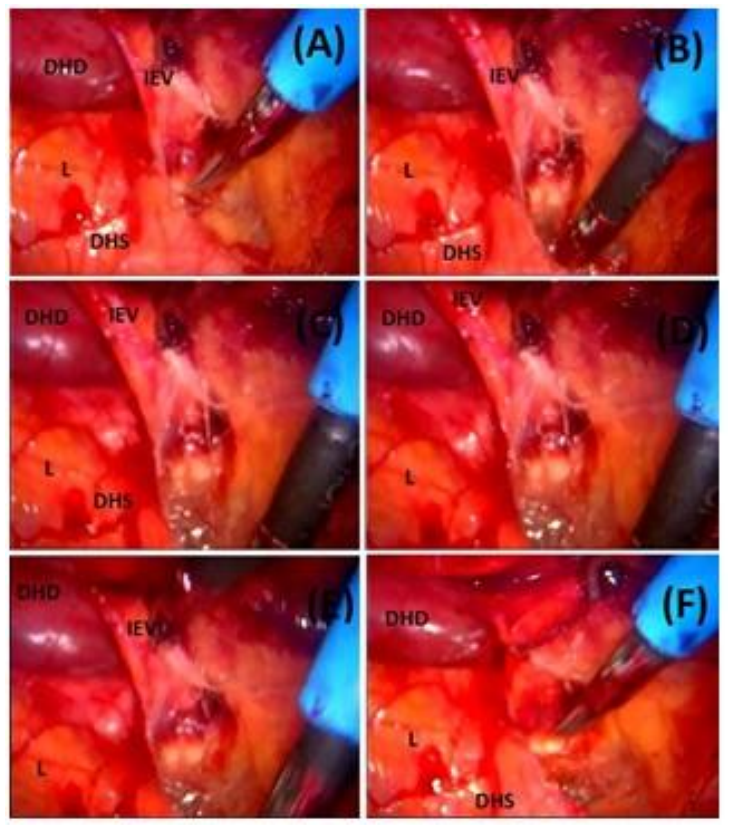

Figure 4: Total extra-peritoneal (TEP) hernioplasty dissection in one patient with right direct inguinal hernia with cord lipoma: A-F, direct hernial sac (DHS) and associated sizable lipoma (L) is being pulled out of the direct hernial defect (DHD). 